\title{
Association of Prognostic Value of Primary Tumor Location in Stage III Colon Cancer With RAS and BRAF Mutational Status
}

\begin{abstract}
Julien Taieb, MD, PhD; Hampig Raphael Kourie, MD; Jean-François Emile, MD, PhD; Karine Le Malicot, MS; Ralyath Balogoun, PhD; Josep Tabernero, MD, PhD; Enrico Mini, MD, PhD; Gunnar Folprecht, MD, PhD; Jean-Luc Van Laethem, MD, PhD; Claire Mulot, MS; Olivier Bouché, MD, PhD; Thomas Aparicio, MD, PhD; Pierre Michel, MD, PhD; Josef Thaler, MD, PhD; John Bridgewater, MD; Eric Van Cutsem, MD, PhD;

Géraldine Perkins, MD, PhD; Come Lepage, MD, PhD; Ramon Salazar, MD, PhD; Pierre Laurent-Puig, MD, PhD; for the Pan-European Trials in Alimentary Tract Cancer (PETACC)-8 Investigators
\end{abstract}

IMPORTANCE We know of no data on the prognostic value of primary tumor location (PTL) according to $B R A F, R A S$, and microsatellite instability (MSI) status in patients who have undergone resection for colon cancer (CC) and have been treated with current standard adjuvant chemotherapy.

OBJECTIVE To determine the prognostic and predictive value of PTL according to $B R A F, R A S$, and MSI status in patients with stage III CC receiving adjuvant treatment with FOLFOX (folinic acid [leucovorin calcium], fluorouracil, and oxaliplatin) with or without cetuximab.

DESIGN, SETTING, AND PARTICIPANTS This post hoc analysis included patients with available tumor blocks of resected stage III colon adenocarcinoma who participated in the Pan-European Trials in Alimentary Tract Cancer (PETACC)-8 phase 3 randomized trial. Among the 2559 patients who underwent randomization, 1900 were screened by next-generation sequencing, which showed that 1869 had full information concerning PTL. We categorized primary tumor site as located proximal (right) or distal (left) to the splenic flexure.

MAIN OUTCOMES AND MEASURES The associations between PTL (right- vs left-sided) and disease-free survival (DFS), survival after relapse (SAR), and overall survival (OS) were assessed by Cox models and adjusted for clinical and pathological features, treatment, and $\mathrm{MSI}, B R A F$, and RAS status.

RESULTS Among the 1869 patients (1056 [57\%] male; mean [SD] age, 59.4 [9.5] years) with full molecular data analyzed, 755 (40\%) had a right-sided tumor, 164 (10\%) had MSI, 942 (50\%) had RAS mutations, and 212 (11\%) had BRAF mutations. Right-sided tumor location was not prognostic for DFS in the whole population but was associated with a shorter SAR (hazard ratio [HR], 1.54; 95\% Cl, 1.23-1.93; $P=.001$ ) and OS (HR, 1.25; 95\% Cl, 1.02-1.54; $P=.03$ ). When looking at DFS in the different molecular subgroups, we found similar results for microsatellite-stable tumors and tumors with MSI; a better DFS in right-sided vs left-sided tumors in patients with $R A S$ mutations ( $\mathrm{HR}, 0.80 ; 95 \% \mathrm{Cl}, 0.64-1.00 ; P=.046$ ); and a worse DFS in right-sided vs left-sided tumors in patients with RAS and BRAF double wild type (HR, $1.39 ; 95 \% \mathrm{Cl}, 1.01-1.92 ; P=.04)$. These results were found independently of the treatment received, and no beneficial effect of cetuximab on DFS or OS was observed in left-sided tumors.

CONCLUSIONS AND RELEVANCE Although right-sided tumor location is associated with poor survival in patients with metastatic CC as previously reported, the association with disease recurrence appears to vary for patients with stage III CC and RAS or BRAF mutations vs those with double wild type.
JAMA Oncol. 2018:4(7):e173695. doi:10.1001/jamaoncol.2017.3695

Published online November 22, 2017
Supplemental content

Author Affiliations: Author affiliations are listed at the end of this article.

Group Information: The PETACC-8 Investigators are listed at the end of the article.

Corresponding Author: Julien Taieb, MD, PhD, Pompidou European Hospital, Department of Hepatogastroenterology and GI Oncology, Sorbonne Paris Cité, Université Paris Descartes, 20 rue Leblanc, 75015 Paris, France (jtaieb75 @gmail.com). 
$\mathrm{B}$ iological and molecular factors such as microsatellite instability (MSI) and KRAS and BRAF mutational status have recently been proposed as prognostic factors in nonmetastatic colorectal cancers and may play a role as stratification factors in future adjuvant trials. ${ }^{1}$

While the prognostic value of primary tumor location (PTL) for overall survival (OS) in metastatic colorectal cancer (mCRC) seems clear and consistent in reports in recent decades, the prognostic impact of PTL for stage III nonmetastatic colorectal cancer remains unclear. Moreover, as many recent publications on PTL deal with patients with $\mathrm{MCRC}$ treated with antiepidermal growth factor receptors, very few data sets report results in patients with $R A S$ mutations. Finally, greater effectiveness of anti-epidermal growth factor receptors in leftsided tumors has also been suggested in patients with mCRC. ${ }^{2}$

We therefore examined the relationship between PTL and disease-free survival (DFS), OS, and survival after recurrence (SAR) in patients with stage III colon cancer (CC) who received adjuvant FOLFOX (folinic acid [leucovorin calcium], fluorouracil, and oxaliplatin) alone or combined with cetuximab. These data were then assessed according to MSI, RAS, and $B R A F$ status and treatment received.

\section{Methods}

The Pan-European Trials in Alimentary Tract Cancer (PETACC-8) study was done in accordance with the Declaration of Helsinki (amended 2000) and the International Conference on Harmonization of Technical Requirements of Pharmaceuticals for Human Use (ICH) Note for Guidance on Good Clinical Practice and approved by the appropriate ethics committees. All patients analyzed gave their informed consent for translational research projects in addition to the informed consent given for the therapeutic trial. Patients with histologically proven stage III resected colon adenocarcinoma for the previously reported PETACC-8 trial were randomly assigned to receive 6 months of FOLFOX or FOLFOX plus cetuximab. ${ }^{3}$ We categorized PTL as on the right or the left of the splenic flexure.

\section{Key Points}

Question Is primary tumor location prognostic or predictive, according to $B R A F, R A S$, and microsatellite instability status, in patients with stage III colon cancer receiving adjuvant FOLFOX (folinic acid [leucovorin calcium], fluorouracil, and oxaliplatin) with or without cetuximab?

Findings In this study of 1869 patients with tumor blocks of resected stage III colon cancer, for those patients with RAS mutant or $B R A F$ mutant genotype, disease-free survival was better with right- vs left-sided tumors; for patients who had RAS and BRAF double wild type, disease-free survival was worse in those with right-sided tumors. No predictive effect of sidedness for cetuximab efficacy was found.

Meaning The association between sidedness and disease recurrence varied between patients with RAS or BRAF wild type and those with a mutation; no beneficial effect of cetuximab on disease-free survival and overall survival in patients with left-sided tumors was seen in the adjuvant setting.

Tumor samples were prospectively banked. Methods for MSI, KRAS, NRAS, and BRAF assessments were previously described. ${ }^{4,5}$

The DFS, OS, and SAR curves were estimated with the Kaplan-Meier method. Differences between groups of patients were analyzed using log-rank tests and Cox models with the SAS statistical software package version 9.4 (SAS Institute). A $P$ value (1-sided) of less than .05 was considered significant.

\section{Results}

\section{Study Population}

Of 2559 patients who underwent randomization, 1900 were screened by next-generation sequencing, which showed that 1869 patients had full information concerning PTL (Figure 1). Of those 1869 patients, 755 (40\%) had right-sided tumors, 164 (10\%) had MSI, 942 (50\%) had RAS mutations, and 212 (11\%)

Figure 1. Flow of Patients in PETACC-8 Trial Molecular Study

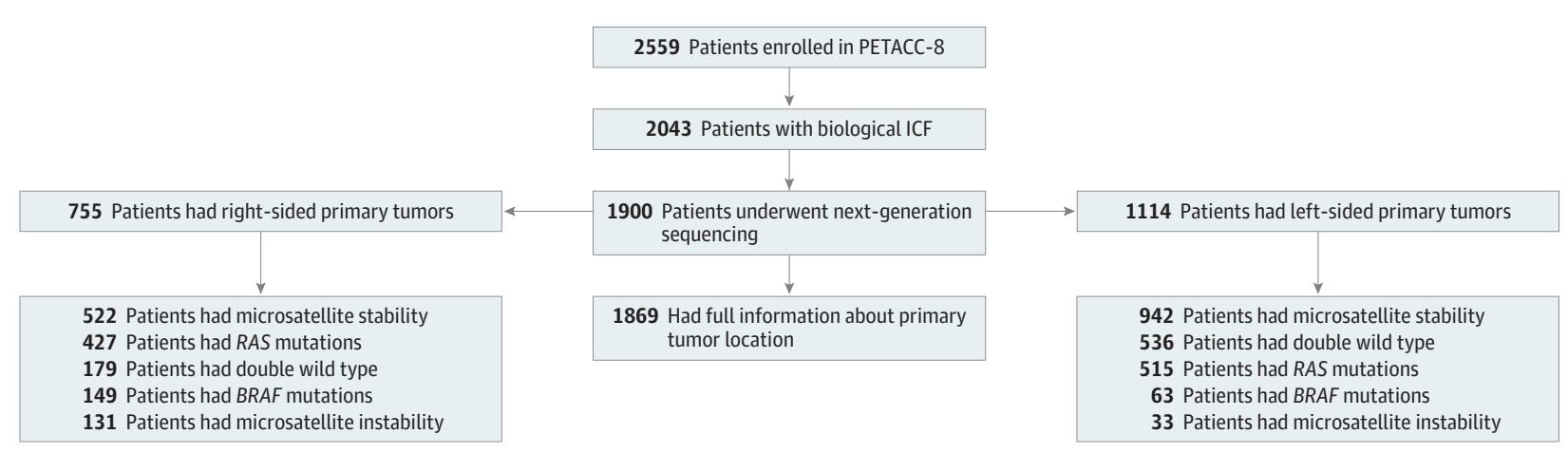

Of 2559 patients who underwent randomization, 1900 were screened by next-generation sequencing, which showed that 1869 had full information concerning PTL. Of those 1869 patients, 755 (40\%) had right-sided tumors,
164 (10\%) had microsatellite instability, 942 (50\%) had RAS mutations, and 212 (11\%) had BRAF mutations. 
A Disease-free survival

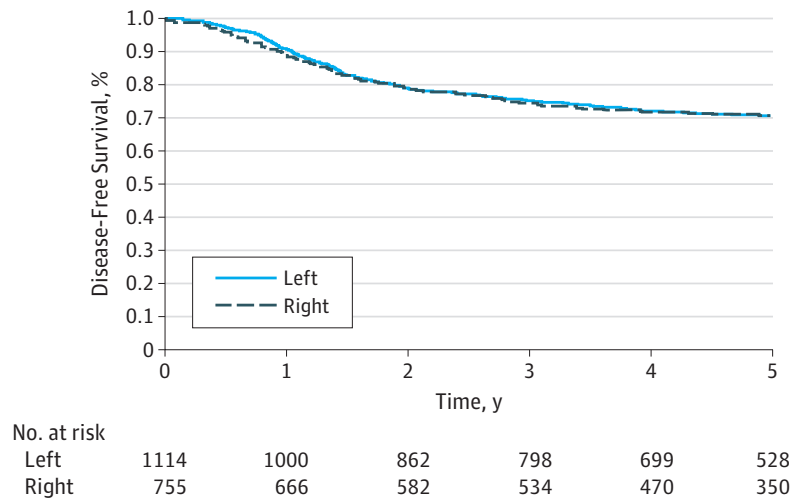

B Overall survival

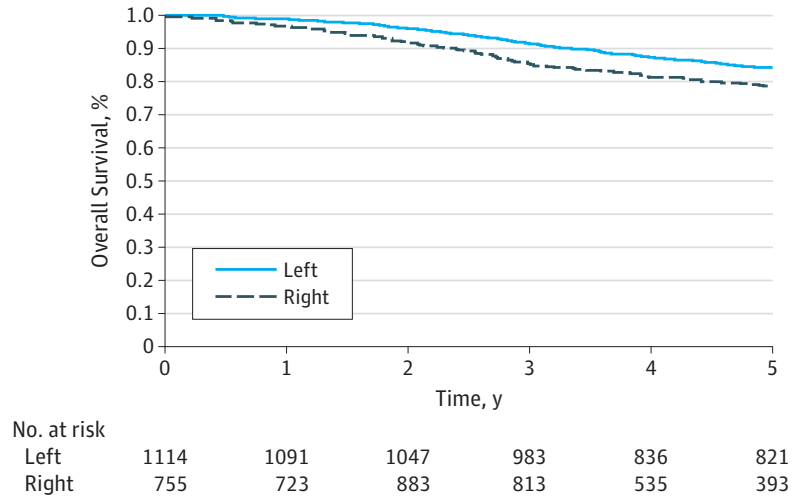

C Survival after recurrence

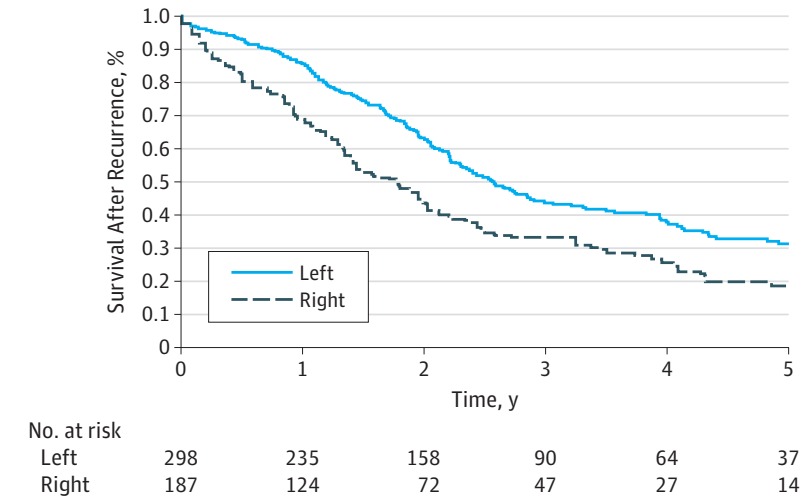
$\begin{array}{lrrrrrr}\text { Left } & 1114 & 1091 & 1047 & 983 & 836 & 821 \\ \text { Right } & 755 & 723 & 883 & 813 & 535 & 393\end{array}$

\begin{tabular}{|lll|}
\hline & $\begin{array}{l}\text { Left localization } \\
(\mathrm{n}=1114)\end{array}$ & $\begin{array}{l}\text { Right localization } \\
(\mathrm{n}=755)\end{array}$ \\
\hline Events, No. & 334 & 224 \\
3-y Disease-free survival, \% $(95 \% \mathrm{Cl})$ & $75.5(72.5-77.6)$ & $74.3(71.0-77.3)$ \\
HR (95\% Cl); $P$ value, log-rank & $1.00(0.85-1.19) ; P=.98$ & \\
Adjusted HR (95\% Cl): $P$ value, Wald & $0.91(0.75-1.11) ; P=.33$ & \\
\hline
\end{tabular}

\begin{tabular}{|lll|}
\hline & $\begin{array}{l}\text { Left localization } \\
(\mathrm{n}=1114)\end{array}$ & $\begin{array}{l}\text { Right localization } \\
(\mathrm{n}=755)\end{array}$ \\
\hline Events, No. & 203 & 165 \\
$5-\mathrm{y} \mathrm{OS}, \%(95 \% \mathrm{Cl})$ & $84.2(81.8-86.3)$ & $78.6(75.4-81.5)$ \\
HR $(95 \% \mathrm{Cl}) ; P$ value, log-rank & $1.25(1.02-1.54) ; P=.03$ & \\
Adjusted HR $(95 \% \mathrm{Cl})$ : $P$ value, Wald & $1.22(0.96-1.55) ; P=.11$ & \\
\hline
\end{tabular}
.

\begin{tabular}{|lll|}
\hline & $\begin{array}{l}\text { Left localization } \\
(\mathrm{n}=1114)\end{array}$ & $\begin{array}{l}\text { Right localization } \\
(\mathrm{n}=187)\end{array}$ \\
\hline Events, No. & 175 & 136 \\
$5-\mathrm{y} \mathrm{OS}, \%(95 \% \mathrm{Cl})$ & $31.1(24.9-37.6)$ & $18.6(12.3-25.8)$ \\
HR $(95 \% \mathrm{Cl}) ; P$ value, Log-rank & $1.54(1.23-1.93) ; P=.001$ \\
Adjusted HR $(95 \% \mathrm{Cl})$ : $P$ value, Wald & $1.78(1.13-1.92) ; P=.005$ \\
\hline
\end{tabular}

A, No difference was noted in disease-free survival when comparing right-sided with left-sided stage III colon cancer in the whole study population. B, Overall survival was significantly better for left-sided tumors. C, Survival after recurrence was significantly better for left-sided tumors. HR indicates hazard ratio.

had BRAF mutations. Demographic and clinical characteristics of the patients in the molecular study $(\mathrm{n}=1869)$ were not statistically different from those excluded from the molecular study ( $n=690)$ (eTable 1 in the Supplement). All demographic and molecular characteristics according to sidedness are summarized in eTable 2 and eTable 3 in the Supplement.
Outcome in the Whole Population

No difference was noted in DFS when comparing right-sided with left-sided stage III CC in the whole study population (Figure 2A). However, SAR (hazard ratio [HR], 1.54; 95\% CI, 1.231.93; $P=.001)$ and OS (HR, 1.25; 95\% CI, 1.02-1.54; $P=.03$ ) were significantly better for left-sided tumors, and 5-year SAR and 
A RAS and BRAF double wild type

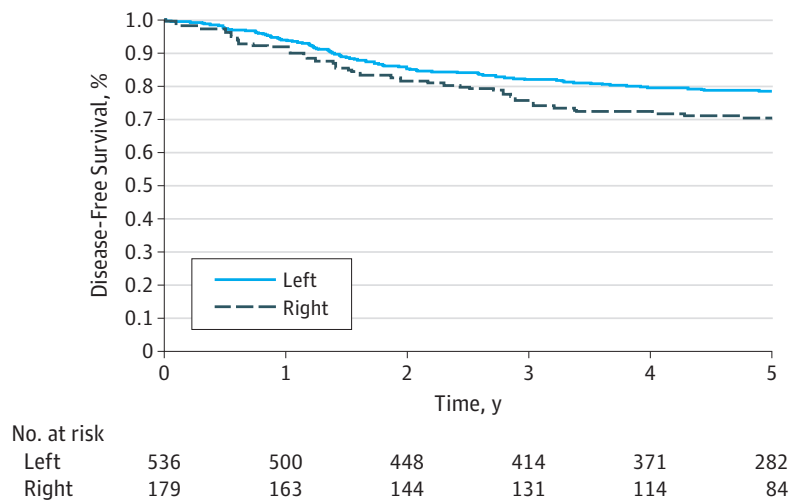

B RAS mutation

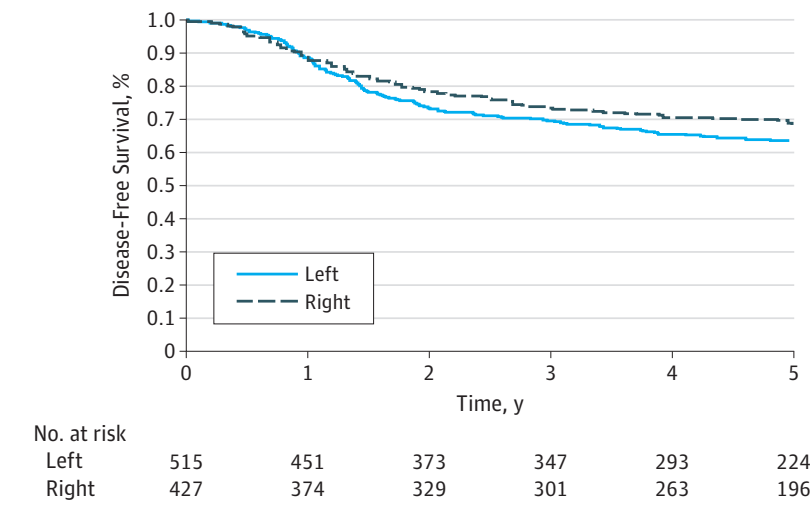

\begin{tabular}{|lll|}
\hline & $\begin{array}{l}\text { Left localization } \\
(\mathrm{n}=536)\end{array}$ & $\begin{array}{l}\text { Right localization } \\
(\mathrm{n}=179)\end{array}$ \\
\hline Events, No. & 119 & 53 \\
3-y, Disease-free survival, \% $(95 \% \mathrm{Cl})$ & $81.9(78.3-84.9)$ & $75.7(68.7-81.4)$ \\
HR $(95 \% \mathrm{Cl}) ; P$ value, log-rank & $1.39(1.01-1.92) ; P=.04$ & \\
Adjusted HR $(95 \% \mathrm{Cl})$ : $P$ value, Wald & $1.22(0.86-1.72) ; P=.27$ & \\
\hline
\end{tabular}

282

\begin{tabular}{|lll|}
\hline & $\begin{array}{l}\text { Left localization } \\
(\mathrm{n}=515)\end{array}$ & $\begin{array}{l}\text { Right localization } \\
(\mathrm{n}=427)\end{array}$ \\
\hline Events, No. & 192 & 131 \\
3-y Disease-free survival, \% $(95 \% \mathrm{Cl})$ & $69.6(67.6-71.6)$ & $73.4(71.2-75.6)$ \\
HR (95\% Cl); $P$ value, log-rank & $\begin{array}{l}0.80(0.64-1.00) ; P=.046 \\
\text { Adjusted HR }(95 \% \mathrm{Cl}) \text { : } P \text { value, Wald }\end{array}$ & $\begin{array}{l}0.75(0.59-0.95) ; P=.02 \\
\end{array}$ \\
\hline
\end{tabular}

A, In patients with RAS and BRAF double wild type, those with right-sided primary tumors had a shorter disease-free survival compared with those with left-sided tumors. B, For RAS-mutated tumors, patients with right-sided primary tumors had a longer disease-free survival compared with those with left-sided tumors.

OS rates were $31.1 \%$ vs $18.5 \%$ and $84.2 \%$ vs $78.6 \%$ for leftsided vs right-sided tumors, respectively (Figure 2B and C).

\section{Multivariable Analysis}

In multivariable analysis, the following were associated with shorter DFS: histopathology grades 3 and 4; TNM categories pT3, pT4, and pN2; RAS mutations; Eastern Cooperative Oncology Group Performance Status (ECOG PS) 1 and 2; and bowel obstruction and/or perforation. Overall survival was also worse in patients with histopathology grades 3 and 4; TNM categories pT3, pT4, and pN2; RAS mutations; ECOG PS 1 and 2; and bowel obstruction and/or perforation. Moreover, patients with MSI tumors had better OS. Only right-sided, grade 3 or 4, pN2, and $B R A F$-mutated tumors were associated with shorter SAR (eTable 4 in the Supplement).

Outcome in Different Molecular Subgroups

All molecular subgroups' outcomes are summarized in eTable 5 in the Supplement.

No difference in DFS was reported for right-sided vs leftsided tumors in microsatellite-stable or MSI tumors (eFigure 1 in the Supplement).
In patients with double wild-type genome, those with right-sided primary tumors had a shorter DFS compared with those with left-sided tumors (HR, 1.39; 95\% CI, 1.01-1.92; $P=.04$ ), with 3-year DFS rates of $75.7 \%$ and $81.9 \%$, respectively (Figure 3A). However, these results were not significant (HR, 1.22; 95\% CI, 0.86-1.72; $P=.26$ ) when adjusted for histopathological grade, pT, pN, ECOG PS, and bowel obstruction and/or perforation.

For RAS-mutated tumors, patients with right-sided primary tumors had a longer DFS compared with those with left-sided tumors (HR, 0.80; 95\% CI, 0.64-1.00; $P=.046$ ), with 3-year DFS of $73.4 \%$ and $69.6 \%$, respectively (Figure 3B). These results were still significant (HR, 0.75; 95\% CI, 0.59-0.95; $P=.02$ ) when adjusted for histopathological grade, pT, pN, ECOG PS, and bowel obstruction and/or perforation in a multivariable model. The same trends were observed when looking at BRAF-mutated tumors (eTable 5 in the Supplement).

Treatment Outcomes in Right-Sided vs Left-Sided CC When separately analyzing patients treated with FOLFOX alone or FOLFOX plus cetuximab, the association of PTL with DFS, 
OS, and SAR was comparable to that described in the general population (eFigure 2 in the Supplement).

In patients with double wild type, there was no statistical difference in DFS when comparing FOLFOX plus cetuximab vs FOLFOX alone in both right-sided tumors (HR, 0.89; 95\% CI, 0.78-1.26; $P=.94$ ) and left-sided tumors (HR, 0.84; 95\% CI, 0.59-1.21; $P=.34$ ) (eFigure 3 in the Supplement).

\section{Discussion}

These data describe the prognostic value of PTL in stage III CC treated with FOLFOX with full RAS, BRAF, and MSI assessment. We confirmed historical data that right-sided tumors were older and more likely to be poorly differentiated, exhibit vascular invasion or lymphatic infiltration, and have MSI and $B R A F$ mutation. ${ }^{6,7}$ Similarly, at disease relapse, rightsided tumors had a worse prognosis. This result is similar in all molecular subgroups presently characterized and is in accordance with the currently published results of PTL prognostic value in the metastatic setting. ${ }^{2}$

However, when looking at disease recurrence, patients with $R A S$-mutated and/or BRAF-mutated right-sided tumors had a better DFS than left-sided tumors. Right-sided tumors remained of poor prognosis regarding DFS only in patients with double wild type.

Some recent studies demonstrated that PTL may be considered as a predictive factor in RAS wild-type mCRC treated with chemotherapy and cetuximab..$^{2,8-11}$ In the present work, no benefit of adding cetuximab to FOLFOX was observed in our population of patients with stage III left-sided tumors; nor was any detrimental effect of adding cetuximab observed in right-sided tumors.

The major strengths of our study are that patients are coming from a randomized, prospective, registration-designed phase 3 trial; that all patients were treated with the current standard FOLFOX chemotherapy regimen (with or without cetuximab) in this setting; and that a full RAS and BRAF mutational profile using next-generation sequencing for all included patients (not limited to KRAS and BRAFV6OOE) was determined together with the MSI assessment.

\section{Limitations}

Our work also has limitations. The post hoc design of the present analysis and the limited number of patients with $B R A F$ mutations and MSI tumors led to small subgroups for some of the analyses performed.

\section{Conclusions}

Although PTL does not seem to be associated with DFS in the whole study population, opposite sidedness prognostic values are observed for RAS and BRAF wild-type and mutant tumors. A larger analysis that uses all currently available adjuvant trials with complete molecular analysis and takes into account other prognostic molecular data from the consensus molecular subtypes ${ }^{12}$ is needed to confirm these first results and to better determine the molecular differences explaining them.

\section{ARTICLE INFORMATION}

Accepted for Publication: August 18, 2017

Published Online: November 22, 2017. doi:10.1001/jamaoncol.2017.3695

Author Affiliations: Sorbonne Paris Cité, Université Paris Descartes, Department of Hepatogastroenterology and GI Oncology, Hôpital Européen Georges Pompidou, Paris, France (Taieb، Kourie); Pathology Department, Ambroise Paré Hospital, Boulogne-Billancourt, France (Emile); Fédération Francophone de Cancérologie Digestive (FFCD), Dijon, France (Le Malicot, Lepage); Université Paris Descartes, Sorbonne Paris Cité, France (Balogoun, Mulot, Laurent-Puig); Assistance Publique-Hôpitaux de Paris, Department of Biology, Hôpital Européen Georges Pompidou, INSERM UMR-S1147, Paris, France (Balogoun, Mulot, Laurent-Puig); Medical Oncology Department, Vall d'Hebron University Hospital and Institute of Oncology (VHIO), CIBERONC, Universitat Autònoma de Barcelona, Spanish Gastrointestinal Tumours TTD Group, Barcelona, Spain (Tabernero); Section of Internal Medicine, Department of Experimental and Clinical Medicine, University of Florence, Florence, Italy (Mini); Medical Department I, University Hospital Carl Gustav Carus, Dresden, Germany (Folprecht); Department of Gastroenterology, Hôpital Universitaire Erasme, Brussels, Belgium (Van Laethem); Department of Hepato-Gastroenterology, Reims University Hospital, Reims, France (Bouché); Gastroenterology Department, CHU Saint Louis, Assistance Publique-
Hôpitaux de Paris and Université Paris 7, Sorbonne Paris Cité, Paris, France (Aparicio); Department of Gastroenterology, Rouen University Hospital, University of Rouen, Rouen, France (Michel); Department of Internal Medicine IV, Klinikum Wels-Grieskirchen, Wels, Austria (Thaler); UCL Cancer Institute, University College London, London, England (Bridgewater); Digestive Oncology, University Hospitals Leuven and KU Leuven, Leuven, Belgium (Van Cutsem, Perkins); Hepato-Gastroenterology Department, Dijon University Hospital and INSERM U 866, Dijon, France (Lepage); Catalan Institute of Oncology (IDIBELL), Universitat de Barcelona, CIBERONC, Spanish Gastrointestinal Tumours TTD Group, Barcelona, Spain (Salazar).

Author Contributions: Drs Taieb and Le Malicot had full access to all of the data in the study and take responsibility for the integrity of the data and the accuracy of the data analysis. Study concept and design: Taieb, Le Malicot, Tabernero, Mini, Thaler, Van Cutsem, Lepage, Salazar, Laurent-Puig.

Acquisition, analysis, or interpretation of data: Taieb, Kourie, Emile, Le Malicot, Balogoun, Tabernero, Mini, Folprecht, Van Laethem, Mulot, Bouché, Aparicio, Michel, Thaler, Bridgewater, Perkins, Lepage, Laurent-Puig. Drafting of the manuscript: Taieb, Kourie, Le Malicot, Tabernero, Laurent-Puig. Critical revision of the manuscript for important intellectual content: All authors.

Statistical analysis: Taieb, Le Malicot, Laurent-Puig.
Obtained funding: Taieb.

Administrative, technical, or material support: Emile, Balogoun, Tabernero, Folprecht, Van Laethem, Mulot, Bouché, Thaler, Bridgewater Lepage.

Study supervision: Taieb, Thaler, Bridgewater,

Salazar, Laurent-Puig.

Conflict of Interest Disclosures: Dr Taieb has participated in consulting and/or advisory boards for Merck KGaA, Sanofi, Roche/Genentech, Pfizer, and Amgen; Dr Tabernero for Amgen, ImClone Systems, Lilly, Millennium, Novartis, Roche/ Genentech, Sanofi, Celgene, Chugai Pharma, Taiho Pharmaceutical, Boehringer Ingelheim, and Merck $\mathrm{KGaA}$; Dr Folprecht for Merck KGaA, Roche/ Genentech, Sanofi-Aventis, Bayer, Lilly, Servier, and Bristol-Myers Squibb; Dr Salazar for Merck KGaA, Amgen, Novartis, and Lilly; and Dr Laurent-Puig for Sanofi, Merck KGaA, Amgen, Roche, Genomic Health, Myriad Genetics, and Pfizer. Dr Bridgewater received honoraria from Merck KGaA; Dr Emile from Amgen and Merck KGaA. Dr Folprecht has received research funding from Merck KGaA. Dr Van Cutsem received research funding from Amgen, Bayer, Boehringer Ingelheim, Celgene, Ipsen, Merck KGaA, Novartis, Roche, and Sanofi. No other disclosures are reported.

Funding/Support: The PETACC-8 study was sponsored by the Fédération Francophone de Cancérologie Digestive (FFCD). Merck KGaA provided the study cetuximab and financial support for study management. Sanofi-Aventis provided 
financial support for the provision of oxaliplatin to Belgian sites when necessary.

Role of Funder/Sponsor: The sponsors had no role in the design and conduct of the study; collection, management, analysis, and interpretation of the data; preparation, review, or approval of the manuscript; and decision to submit the manuscript for publication. Merck KGaA reviewed the manuscript for medical accuracy before journal submission. The FFCD was responsible for study management, and Merck KGaA provided financial support for study management.

PETACC-8 Investigators: Austria; Austrian Breast and Colorectal cancer Study Group (ABCSG);

Josef Thaler (coordinator and principal investigator [PI]; Klinikum Kreuzschwestern Wels, Wels); Richard Greil (LKH Salzburg); Johannes Gaenzer (BKH Hall in Tirol, Hall in Tirol); Wolfgang Eistere (University Klinik Innsbruck, Innsbruck); Joerg Tschmelitsch (KH Barmherzige Brüder St. Veit / Glan); Felix Keil (LKH Leoben, Leoben); Hellmut Samonigg (Landeskrankenhaus Graz Medizinische Universitätsklinik, Graz); August Zabernigg (BKH Kufstein, Kuftstein); Franz Schmid (LKH Bregenz, Bregenz); Günther Steger (Universitätsklinik für Innere Medizin I, Wein); Robert Steinacher (LKH Wolfsberg, LKH); Johannes Andel (LKH Steyr, Steyr); Björn Jagdt, (a.ö.Krankenhaus d. Barmherz. Schwest. Ried, Ried); Alois Lang (LKH Rankweil, Rankweil), Michael Fridrik (AKH Linz, Linz) Reinhold Függer (A.ö. Krankenhaus d. Elisabethinen Linz); Friedrich Hofbauer (LKH Oberpullendorf, Oberpullendorf); Ewald Woell (KH St. Vinzenz Zams, Zams); Dietmar Geissler (LKH Klagenfurt, Klagenfurt); Alfred Lenauer (KH Wiener Neustadt, Wiener Neustadt); Manfred Prager (A.ö. KH Oberwart, Oberwart); Belgium; Belgian Group of Digestive Oncology (BGDO); Geert D'Haens (Imelda Ziekenhuis, Bonheiden); Gauthier Demolin (Clinique St-Jospeh, Liège); Joseph Kerger (Cliniques Universitaires de Mont-Godinne U.C.L. Yvoir); Guido Deboever (A. Z. St-Jozef, Oostende); Gilbert Ghillebert (Heilig Hart Ziekenhuis, Roeselare); Marc Polus (C. H. U. Sart-Tilman, Liège); Eric Van Cutsem (coordinator and PI; University Hospitals, Leuven); Hassan Rezaie Kalantari (C. H. Peltzer-La Tourelle, Verviers); Thierry Delaunoit (Centre Hospitalier de Jolimont-Lobbes, La Louvière); Jean Charles Goeminne (Clinique et Maternité Sainte-Elisabeth, Namur); Marc Peeters (Universitair Ziekenhuis Gent, Gent); Philippe Vergauwe (AZ Groeninge-Campus Kennedylaan, Kortrijk); Ghislain Houbiers (Centre médical de L'Avenue, Liege); Yves Humblet (Cliniques Universitaires Saint-Luc, Brussels); Jos Janssens (St-Elisabeth Ziekenhuis, Turnhout); Dirk Schrijvers (ZNA Middelheim, Antwerpen); Erik

Vanderstraeten (AZ Maria Middelares, Gent) Jean-Luc Van Laethem (coordinator and PI; ULB Hôpital Erasme, Brussels); Jan Vermorken (UZ Antwerpen, Edegem); Daniel Van Daele (Clinique Nôtre-Dame de Grâce, Gosselies); Michel Ferrante (AZ Sint-Maarten, Mechelen,); Frederic Forget (Centre Hospitalier de l'Ardenne, Libramont); Alain Hendlisz (Jules Bordetinstituut, Brussels); Denmark; Lone Nørgård Petersen (coordinator and PI); Mette Yilmaz (Aalborg Sygehus-Afsnit Syd, Aalborg); Svend Erik Nielsen (Hillerød Hospital Hillerød); Lene Vestermark (Odense Universitets Hospital, Odense); Jim Larsen (Roskilde Amtssygehus, Roskilde); France; Fédération Francophone de Cancérologie Digestive (FFCD); Fédération Nationale des Centres de Lutte
Contre le Cancer (UNICANCER); Fédération Nationale des Centres de Lutte Contre le Cancer Association Européenne de Recherche en Oncologie (AERO); Mohamed-Ayman Zawadi (coordinator and PI; Centre Hospitalier Les Oudairies, La Roche sur Yon); Olivier Bouche (CHU de Reims, Hopital Robert Debre, Reims): Laurent Mineur (Institut Sainte Catherine, Avignon); Jaafar Bennouna-Louridi (CRLCC René Gauducheau, St Herblain); Louis Marie Dourthe, (Clinique Sainte Anne, Strasbourg); Marc Ychou (coordinator and PI; Centre Regional Val d'Aurelle Paul Lamarque, Montpellier); Eveline Boucher (CRLC Eugène Marquis, Rennes); Julien Taieb (Hôpital Européen Georges Pompidou, Paris); Denis Pezet (CHU Estaing, Clermond Ferrand); Francoise Desseigne (Centre Leon Berard, Lyon); Michel Ducreux (Institut Gustave Roussy Villejuif); Patrick Texereau (Hopital Layne, Mont-de-Marsan); Laurent Miglianico (Centre Hospitalier Privé Saint- Grégoire (Rennes), Saint-Grégoire); Philippe Rougier (Hôpital Européen Georges Pompidou, Paris); Serge Fratte (Centre Hospitalier de Belfort-Montbeliard, Belfort); Charles-Briac Levache (Polyclinique Francheville, Perigueux); Yacine Merrouche, (Institut de Cancerologie de la Loire,

Saint-Priest-En-Jarez); Stephen Ellis (Clinique Saint Pierre, Perpignan); Christophe Locher (CH Meaux Meaux); Jean-Francois Ramee (Centre Catherine de Sienne, Nantes); Claire Garnier (UMGEC-Institut Daniel Hollard, Grenoble); Frederic Viret (Institut Paoli Calmettes, Marseille); Bruno Chauffert (Centre Georges François Leclerc, Dijon); Isabelle Cojean-Zelek (Hopital Croix Saint Simon, Paris); Pierre Michel (Hopital Charles Nicolle, Rouen); Cedric Lecaille (Polyclinique Bordeaux Nord Aquitaine, Bordeaux); Christian Borel (CLCC Paul Strauss, Strasbourg); Jean-Francois Seitz (coordinator and $\mathrm{Pl}$; $\mathrm{CHU}$ de la Timone, Marseille); Denis Smith (Groupe Hospitalier Saint-Andre, Bordeaux); Catherine Lombard-Bohas (Hospices Civils de Lyon, Hôpital Edouard Herriot, Lyon) Thierry Andre (Groupe Hospitalier PitieSalpetriere, Paris); Jean-Marc Gornet, (Hopital Saint Louis, Paris); Francine Fein (CHU de Besancon, Hopital Jean Minjoz, Besançon); Marie-Aude CoulonSfairi (Centre Hospitalier du Mans, Le Mans); Marie-Christine Kaminsky (Centre Alexis Vautrin Brabois, Vandoeuvre les Nancy); Jean-Paul Lagasse (CHR d' Orléans La Source, Orléans); Dominique Luet (CRLCC Paul Papin, Angiers); Pierre-Luc Etienne (Clinique Armoricaine de Radiologie, Saint-Brieux); Mohamed Gasmi (Hopital Nord de Marseille, Marseille); Andre Vanoli (Clinique Ste-Marie, Chalon Sur Saone); Suzanne Nguyen (Centre Hospitalier de Beauvais, Beauvais); Thomas Aparicio (Hôpital Bichat, Paris); Hervé Perrier (Hopital Saint Joseph, Marseille); Noel Stremsdoerfer (Hopital Pierre Oudot, BourgoinJallieux); Philippe Laplaige (Clinique Saint Côme, La Chaussée St Victor); Dominique Arsene (CHU de Caen, Caen); Dominique Auby (Hôpital Robert Boulin, Libourne); Laurent Bedenne (Hopital du Bocage, Dijon); Romain Coriat (Hopital Cochin, Paris); Bernard Denis (Hopital Pasteur, Colmar); Patrick Geoffroy (Clinique Saint-Vincent, Epernay) Gilles Piot (Clinique des Ormeaux, Le Havre); Yves Becouarn (CHU de Bordeaux, Bordeaux); Gilbert Bordes (Centre Hospitalier de Digne Les Bains, Digne Les Bains); Gael Deplanque (Hopital Saint Joseph, Paris); Olivier Dupuis (Clinique Victor Hugo, Le Mans); Frederic Fruge (CHU Poitiers-Hôpital la Milétrie, Poitiers); Rosine Guimbaud (Hopital
Purpan,Toulouse); Thierry Lecomte (Hopital Trousseau - CHU de Tours, Tours); Gérard Lledo (Hopital Prive Jean Mermoz, Lyon); Iradej Sobhani (Hôpital Henri Mondor (GastroEntérologie), Créteil); Amani Asnacios (Hopital Antoine Beclere, Clamart); Ahmed Azzedine (Boulat, Michel, Avignon); Christophe Desauw (Hopital Saint Vincent de Paul-GHICL Lille, Lille); Marie-Pierre Galais (Centre François Baclesse, Caen); Dany Gargot (Centre Hospitalier de Blois, Blois); You-Heng Lam (Hopital de Cholet, Cholet); Abakar Abakar-Mahamat (Hopital l'Archet II, Nice); Jean-Francois Berdah (Clinique Sainte Marguerite, Hyères); Sylviane Catteau (Hopital Duchenne, Boulogne sur Mer); MarieChristine Clavero-Fabri (Clinique Hartman, Levallois Perret); Jean-Francois Codoul (Hopital de Draguignan, Draguignan); Jean-Louis Legoux (Hôpital Haut Levêque, Pessac); Denis Goldfain (Centre Hospitalier General de Dreux, Dreux); Pierre Guichard (Clinique des quatre Pavillons, Lormont); Denis Pere Verge (Hôpital de la Croix Rousse (Gastroentérologie), Lyon); Jocelyne Provencal (Centre Hospitalier d'Annecy, Pringy); Bruno Vedrenne (Hopital E. Muller, Mulhouse); Catherine Brezault-Bonnet (Hopital de Rambouillet, Rambouillet); Denis Cleau (Centre Hospitalier Intercommunal de Vesoul, Vesoul); Jean-Paul Desir (Clinique Pole Sante Republique,

Clermont-Ferrand); David Fallik (Polyclinic Jeanne d'Arc Gien); Bruno Garcia (Clinique de Courlancy, Reims); MarieHélène Gaspard (Clinique Claude Bernard, Albi); Dominique Genet (Centre de Cancerologie Chenieux, Limoges); Johannes Hartwig (Infirmerie Protestante de Lyon, Caluire et Cuire,); Yves Krummel (Centre Hospitalier Selestat, Selestat); Tamara Matysiak Budnik (CH de Nantes Hotel Dieu, Nantes); Vanessa Palascak- Juif (Hopital de Hautepierre, Strasbourg); Harizo Randrianarivelo (Centre Frederic Joliot, Rouen); Yves Rinaldi (Clinique Clairval, Marseille); Albert Aleba (Centre Hospitalier de Niort, Hopital Georges Renon, Niort); Ariane Darut-Jouve (Centre d'oncologie et Radiotherapie, Dijon); Aimery de Gramont (Hopital Saint Antoine, Paris); Herve Hamon (Centre Hospitalier de Valence, Valence); Frederic Wendehenne (Clinique Charcot, Sainte-Foy-les-Lyon); Germany; Arbeitsgemeinschaft Internistische Onkologie (AIO); Axel Matzdorff (Caritasklinik St. Theresia, Saarbruecken); Michael Konrad Stahl (Kliniken EssenMitte-PS, Essen); Wolfgang Schepp (KKH Muenchen Bogenhausen, Muenchen); Martin Burk (Klinikum der Stadt Hanau, Hanau); Lothar Mueller (Onkologische Schwerpunktpraxis, Leer); Gunnar Folprecht (coordinator and PI;

Universitaetsklinikum Carl Gustav Carus, Dresden); Michael Geissler (Staedtische Kliniken Esslingen, Esslingen); Luisa Mantovani-Loeffler (Staedtisches Klinikum St. Georg Leipzig, Leipzig); Thomas Hoehler (Prosper-Hospital, Recklinghausen); Walter Asperger (Krankenhaus St. Elisabeth und St. Barbara, Halle); Hendrik Kroening (Gemeinschaftspraxis, Magdeburg); Ludwig Fischer von Weikersthal (MVZ Gesundheitszentrum St. Marien GmbH, Amberg); Stefan Fuxius (Onkologische Praxis, Heidelberg); Matthias Groschek (Haematologisch-Onkologische Praxis Wuerselen, Wuelselen); Johannes Meiler, Tanja Trarbach (Universitaetsklinikum Essen, Essen); Jacqueline Rauh (Gemeinschaftspraxis Ardeystrasse, Witten); Nicolas Ziegenhagen, Albrecht Kretzschmar (HeliosKliniken Berlin Berlin); Ullrich Graeven (Kliniken Maria Hilf GmbH Moenchengladbach); Arnd Nusch (Onkologische 
Praxis, Velbert); Goetz von Wichert (Universitaetsklinikum, Ulm); Ralf-Dieter Hofheinz (Klinikum der Stadt Mannheim, Mannheim); Gerhard Kleber (Ostalb-Klinikum Aalen, Aalen); Karl-Heinz Schmidt (Johanniter-Krankenhaus Rheinhausen, Duisberg); Ursula Vehling-Kaiser (Gemeinschaftspraxis, Landshut); Claudia Baum, Jochen Schuette (Marien Hospital Duesseldorf $\mathrm{GmbH}$, Duesseldorf); Georg Martin Haag (Universitaetsklinikum Heidelberg, Heidelberg); Wilhelm Holtkamp (Ammerland-Klinik GmbH, Westerstede); Jochen Potenberg (Evangelisches Waldkrankenhaus, Berlin); Tobias Reiber (Praxis fuer Haematologie/Onkologie, Freiberg); Georg Schliesser (Praxis fuer Haematologie und Onkologie, Giessen); Hans-Joachim Schmoll (Martin-LutherUniversitaet Halle-Wittenberg, Halle); Wolfgang Schneider-Kappus (Arztpraxis, Ulm); Wolfgang Abenhardt (Onkologie Praxis im Elisenhof, Muenchen); Claudio Denzlinger (Marienhospital Stuttgart, Stuggart); Jan Henning, Bartscht Marxsen (Universitaetsklinikum Schleswig-Holstein, Luebeck); Hans Guenter Derigs (Staedtische Kliniken Frankfurt-Hoechst, Frankfurt); Helmut Lambertz (Klinikum Garmisch-Partenkirchen, Garmisch-Partenkirchen); Ingulf Becker-Boost (MVZ Duisburg Sued GmbH Duisburg); Karel Caca (Klinikum Ludwigsburg, Ludwigsburg); Christian Constantin (Kliniken Lippe-Lemgo GmbH, Lemgo); Thomas Decker (Gemeinschaftspraxis, Ravensburg); Henning Eschenburg (Internistische Gemeinschaftspraxis, Guestrow); Sigrun Gabius (Gemeinschaftspraxis, Rosenheim); Holger Hebart (Klinikum Schwaebisch Gmuend-Stauferklinik, Mutlangen); Albrecht Hoffmeister (Universitaetsklinikum Leipzig, Leipzig); Heinz-August Horst

(Universitaetsklinikum SchleswigHolstein-Campus Kiel, Kiel); Stephan Kremers (Caritas-Krankenhaus, Lebach); Malte Leithaeuser (Universitaetsmedizin Rostock, Rostock); Sebastian Mueller (Ambulantes Onkologie Zentrum, Ansbach); Siegfried Wagner (Klinikum Deggendorf, Deggendorf); Severin Daum (Charité Universitaetsmedizin BerlinCampus Charité Mitte, Berlin); Frank Schlegel (St. Antonius-Hospital, Eschweiler); Martina Stauch (Onkologische Schwerpunktpraxis, Kronach); Volker Heinemann (Klinikum

der Ludwig-Maximilians-Universitaet, Muenchen); Italy; Gruppo Italiano per lo Studio dei Carcinomi dell'Apparato Digerente (GISCAD); Gruppo Oncologico dell'Italia Meridionale (GOIM); Istituto Oncologico Romagnolo (IOR); Gruppo Cooperativo Chirurgico Italiano (GOCCI);Gruppo Oncologico Nord Ovest (GONO); Gruppo Oncologico Italiano di Ricerca Clinica (GOIRC); Giuseppe Colucci (coordinator and PI); Evaristo Maiello (IRCCS Casa Sollievo della Sofferenza, San Giovanni Rotondo); Luciano Latini (Ospedale di Macerata, Macerata); Alberto Zaniboni (Fondazione Poliambulanza Istituto Ospedaliero, Brescia); Dino Amadori (coordinator and PI; Istituto Scientifico Romagnolo per lo Studio e la Cura dei Tumori, Meldola); Giuseppe Aprile (Az. Policlinico Universitario di Udine, Udine); Sandro Barni (Azienda Ospedaliera Treviglio-Caravaggio, Treviglio); Rodolfo Mattioli (Ospedale Santa Croce ASUR 3, Fano); Andrea Martoni, Francesca di Fabio (Azienda Ospedaliera Universitaria Policlinico Sant'Orsola Ma, Bologna); Rodolfo Passalacqua (Azienda Ospedaliera Istituti Ospitalieri di Cremona, Cremona); Mario Nicolini, Enzo Pasquini (Ospedale Cervesi, Cattolica); Carla Rabbi, Enrico Aitini
(Azienda Ospedaliera Carlo Poma, Mantova); Alberto Ravaioli, Emiliano Tamburini (Ospedale degli Infermi, Rimini); Carlo Barone (Policlinico Universitario Agostino Gemelli, Roma); Guido Biasco (Ospedale Marcello Malpighi Policlinico Sant'Orsola, Bologna); Stefano Tamberi, Angelo Gambi (Ospedale Degli Infermi, Faenza); Claudio Verusio (Ospedale di Saronno, Saronno); Marina Marzola, Giorgio Lelli (Azienda Ospedaliera Universitaria Arcispedale Sant'Anna, Cona (Ferrara)); Corrado Boni (coordinator and PI; A.O Arcispedale Santa Maria Nuova, Reggio Emilia); Stefano Cascinu (Azienda Ospedaliero Universitaria Ospedali Riuniti, Ancona); Paolo Bidoli, Massimo Vaghi (Azienda Ospedaliera San Gerardo, Monza); Giorgio Cruciani (Ospedale Umberto I, Luggo): Francesco Di Costanzo (Azienda Ospedaliera Universitaria Careggi, Firenze); Alberto Sobrero (Azienda Ospedaliera San Martino, Genoa); Enrico Mini (coordinator and PI), Stefania Nobili (A.O. Universitaria Careggi, Firenze); Roberto Petrioli (A.O.U. Senese Policlinico Santa Maria alle Scotte, Siena); Massimo Aglietta (Istituto per la Ricerca e la Cura del Cancro, Candiolo); Oscar Alabiso (Ospedale Maggiore della Carità, Novara); Federico Capuzzo, Alfredo Falcone (coordinator and PI; Presidio Ospedaliero di Livorno, Livorno); Domenico Cristi Corsi (Ospedale "S. Giov. Calibita" Fatebenefratelli, Roma); Roberto Labianca (coordinator and PI; Ospedali Riuniti di Bergamo، Bergamo); Stefania Salvagni (Azienda Ospedaliera di Parma, Parma); Silvana Chiara (Istituto nazionale per la ricerca sul cancro, Genova) Libero Ciuffreda (A.O. San Giovanni Battista, Torino); Francesco Ferraù (Azienda Ospedaliera San Vincenzo, Taormina); Francesco Giuliani (Istituto Oncologico Giovanni Paolo II IRCCS, Bari); Sara Lonardi (IOV-Istituto Oncologico Veneto IRCCS, Padova); Nicola Gebbia, Antonio Russo (Azienda Ospedaliero Universitaria Policlinico Paolo Giaccone, Palermo); Giovanni Mantovani, Elena Massa (Università di Cagliari-Presidio Policlinico Monserrato, Monserrato); Portugal; Gruppo Cooperativo do Cancro Digestivo da Associação Portuguesa de Investigação Oncológica (GCCD, APIO); Evaristo Sanches (coordinator and PI; Instituto Português de Oncologia do Porto Francisco Gentil, Porto); Juan Carlos Mellidez (Hospital Distrital de Aveiro, Aveiro); Pedro Santos (Hospital São Sebastião, EPE, Santa Maria da Feira); Joao Freire (Instituto Portugues de Oncologia, Lison); Cristina Sarmento (Hospital de Sao Joao, Porto); Luis Costa (Hospital de Santa Maria, Lisbon); Antonio Moreira Pinto (Hospital Geral de Santo Antonio, Porto); Sergio Barroso (Hospital Distrital de Beja, Beja); Jorge Espirito Santo (Hospital do Barreiro, Barreiro); Fátima Guedes (Hospital Distrital Figueira da Foz, EPE, Figueira da Foz); Amélia Monteiro (Hospital São Teotónio, EPE, Viseu); Anabela Sa (Hospitais da Universidade de Coimbra, Coimbra); Irene Furtado (Hospital Distrital de Faro, Faro); Spain; Grupo Español para el Tratamiento de los Tumores Digestivos (TTD); Ramon Salazar (ICO ÍHospitalet Hospital Duran i Reynals, Barcelona); Enrique Aranda Aguilar (Hospital Reina Sofia, Cordoba); Fernando Rivera Herrero (Hospital Universitario Marques de Valdecilla, Santander); Josep Tabernero (coordinator and PI; Hospital. Vall d́Hebron, Barcelona); Javier Sastre Valera (Hospital Clinico San Carlos, Madrid); Manuel Valladares Ayerbes (Complejo Hospitalario Universitario A Coruña, A Coruña); Jaime Feliu Batlle (Hospital Universitario La Paz, Madrid); Silvia Gil (Hospital Carlos Haya,
Malaga ; Albert Abad Esteve (ICO

Badalona-Hospital Germans Trias i Pujol, Barcelona); Carlos Garcia-Giron (Hospital Universitario de Burgos, Burgos); Guillermo Lopez Vivanco (Hospital de Cruces, Vizcaya); Antonia Salud Salvia (Hospital Universitario de Lleida Arnau de Vilanova, Lleida); Vicente Alonso Orduña (Hospital Miguel Servet, Zaragoza); Ruth Vera Garcia (Complejo Hospitalario de Navarra, Pamplona); Javier Gallego (HGU de Elche, Elche-Alicante); Bartomeu Massuti Sureda (Hospital General Universitario de Alicante, Alicante); Jordi Remon (Hospital de Mataro, Barcelona); Maria Jose Safont Aguilera (Hospital General Universitario de Valencia, Valencia); Luis Cirera Nogueras (Hospital Mutua de Terrassa, Barcelona); Bernado Queralt Merino (Hospital Universitari de Girona Dr Josep Trueta, Girona); Cristina Gravalos Castro (Hospital 12 de Octubre, Madrid); Purificacion Martinez de Prado (Hospital de Basurto, Bilbao); Carlos Pijaume Pericay (Consorci Hospitalari Parc Tauli, Barcelona); Manuel Constenla Figueiras (Hospital Provincial de Pontevedra, Pontevedra); Inmaculada Guasch Jordan (Hospital Sant Joan de Deu de Manresa, Manresa); Maria Jose Gome Reina (Hospital del Mar, Cadiz); Amelia Lopez-Ladron Garcia (Hospital El Tomillar-Ntra Sra de Valme, Sevilla); Antonio Arrivi Garcia-Ramos (Fundacion Hospital Son Llatzer, Palma Mallorca); Andres Cervantes (Hospital Clinico Universitario de Valencia, Valencia); Carlos Fernandez Martos (Instituto Valenciano de Oncologia, Valencia); Eugenio Marcuello Gaspar (Hospital de la Santa Creu i Sant Pau, Barcelona); Ines Cabezas Montero (Hospital Universitario Sant Joan de Reus, Tarragona); Pilar Escudero Emperador (Hospital Clinico Universitario Lozano Blesa, Zaragoza); Ana Leon Carbonero (Fundacion Jimenez Diaz, Madrid); Manuel Gallen Castillo (Hospital del Mar, Barcelona); Teresa Garcia Garcia (Hospital Morales Meseguer, Murcia); Jose Garcia Lopez (Hospital Universitario Ramón y Cajal, Madrid); Encarnacion Gonzalez Flores (Hospital Virgen de las Nieves Ruiz de Alda, Granada); Monica Guillot Morales (Hospital Son Espases, Palma de Mallorca); Marta Llanos Muñoz (Hospital Universitario de Canarias, Santa Cruz de Tenerife); Ana López Martín (Hospital Severo Ochoa,); Joan Maurel (Hospital Clinic i Provincial, Barcelona); Juan Carlos Camara (Fundacion Hospital Alcorcon, Madrid); Rosario Dueñas Garcia (Hospital Ciudad de Jaen, Jaen); Mercedes Salgado (Complejo Hospitalario Ourense, Ourense); Isabel Hernandez Busquier (Hospital Provincial Castellon, Castellon) Teresa Checa Ruiz (Instituto de Oncologia Corachan, Barcelona); Adelaida Lacasta Muñoa (Hospital. de Donostia, San Sebastian); Miquel Nogue Aliguer (Hospital General de Vic, Vic); Amalia Velasco Ortiz de Taranco (Hospital Universitario de La Princesa, Madrid); Miguel Mendez Ureña (Hospital General de Mostoles, Mostoles); Ferran Losa Gaspa (Consorci Sanitari Creu Roja, Barcelona); Jose Juan Ponce (Hospital Virgen de los Lirios, Alicante); Carlos Bosch Roig (Hospital Universitario. Dr. Peset, Valencia); Pedro Valero Jimenez (Clínica Infanta Luisa, Sevilla); Antonio Galan Brotons (Hospital Sagunto, Sagunto); Santiago Albiol Rodriguez (Hospital Espiritu Santo, Barcelona); Jose Ales Martinez (Hospital Ruber Internacional de Madrid, Madrid); Liliana Canosa Ruiz (Hospital Torrecardenas, Almeria); Margarita Centelles Ruiz (Hospital Sagrat Cor, Barcelona); United Kingdom; John Bridgewater (coordinator and PI; North Middlesex University Hospital NHS 
Trust, London); Rob Glynne-Jones (Centre for Cancer Treatment, Mount Vernon Hospital, Northwood, London); Saad Tahir (Broomfield Hospital, Chelmsford); Tamas Hickish (Poole Hospital NHS Trust, Poole and Bournemouth Hospital, Bournemouth); Jim Cassidy (Beatson West of Scotland Cancer Centre, Glasgow); Leslie Samuel (Aberdeen Royal Infirmary, Aberdeen)

Disclaimer: The authors are fully responsible for the content of this manuscript, and the views and opinions described in the publication reflect solely those of the authors.

\section{REFERENCES}

1. Taieb J, Le Malicot K, Shi Q, et al. Prognostic value of $B R A F$ and $K R A S$ mutations in MSI and MSS stage III colon cancer. J Natl Cancer Inst. 2016;109 (5): djw272.

2. Arnold D, Lueza B, Douillard JY, et al. Prognostic and predictive value of primary tumour side in patients with RAS wild-type metastatic colorecta cancer treated with chemotherapy and EGFR directed antibodies in six randomized trials. Ann Oncol. 2017;28(8):1713-1729.

3. Taieb J, Tabernero J, Mini E, et al; PETACC-8 Study Investigators. Oxaliplatin, fluorouracil, and leucovorin with or without cetuximab in patients with resected stage III colon cancer (PETACC-8): an open-label, randomised phase 3 trial. Lancet Oncol. 2014;15(8):862-873.

4. Taieb J, Zaanan $\mathrm{A}$, Le Malicot $\mathrm{K}$, et al. Prognostic effect of $B R A F$ and $K R A S$ mutations in patients with stage III colon cancer treated with leucovorin, fluorouracil, and oxaliplatin with or without cetuximab: a post hoc analysis of the PETACC- 8 trial. [Published online January 14, 2016]. JAMA Oncol. doi:10.1001/jamaoncol.2015.5225.

5. Taieb J, Balogoun R, Le Malicot K, et al; PETACC8 Investigators. Adjuvant FOLFOX +/- cetuximab in full RAS and BRAF wildtype stage III colon cancer patients. Ann Oncol. 2017;28(4):824-830.

6. Benedix F, Kube R, Meyer F, Schmidt U, Gastinger I, Lippert H; Colon/Rectum Carcinomas (Primary Tumor) Study Group. Comparison of 17,641 patients with right- and left-sided colon cancer: differences in epidemiology, perioperative course, histology, and survival. Dis Colon Rectum. 2010; 53(1):57-64.

7. Jess P, Hansen IO, Gamborg M, Jess T; Danish Colorectal Cancer Group. A nationwide Danish cohort study challenging the categorisation into right-sided and left-sided colon cancer. BMJ Open. 2013;3(5):e002608.

8. Venook AP, Niedzwiecki D, Innocenti F, et al. Impact of primary $\left(1^{\circ}\right)$ tumor location on overall survival (OS) and progression-free survival (PFS) in patients (pts) with metastatic colorectal cance
(mCRC): analysis of CALGB/SWOG 80405 (Alliance). J Clin Oncol. 2016;34(15)(suppl):3504 doi:10.1200/JCO.2016.34.15_suppl.3504

9. Heinemann V, Modest DP, von Weikersthal LF, et al. Gender and tumor location as predictors for efficacy: influence on endpoints in first-line treatment with FOLFIRI in combination with cetuximab or bevacizumab in the AIO KRK 0306 (FIRE3) trial. J Clin Oncol. 2014;32(15)(suppl) 3600.doi:10.1200/JCO.2014.32.15_suppl.3600

10. Douillard JY, Siena S, Cassidy J, et al. Randomized, phase III trial of panitumumab with infusional fluorouracil, leucovorin, and oxaliplatin (FOLFOX4) versus FOLFOX4 alone as first-line treatment in patients with previously untreated metastatic colorectal cancer: the PRIME study. J Clin Oncol. 2010;28(31):4697-4705.

11. Schwartzberg LS, Rivera F, Karthaus M, et al. PEAK: a randomized, multicenter phase II study of panitumumab plus modified fluorouracil, leucovorin, and oxaliplatin (mFOLFOX6) or bevacizumab plus mFOLFOX6 in patients with previously untreated, unresectable, wild-type KRAS exon 2 metastatic colorectal cancer. J Clin Oncol. 2014:32(21):2240-2247.

12. Guinney J, Dienstmann $R$, Wang $X$, et al. The consensus molecular subtypes of colorectal cancer Nat Med. 2015:21(11):1350-1356. 